\title{
Agoraphobia in adults: incidence and longitudinal relationship with panic
}

\author{
O. JOSEPH BIENVENU, CHIADI U. ONYIKE, MURRAY B. STEIN, \\ LI-SHIUN CHEN, JACK SAMUELS, GER ALD NESTADT and WILLIAM W. EATON
}

\author{
Background Theories regarding how \\ spontaneous panic and agoraphobia relate \\ are based mostly on cross-sectional \\ and/or clinic data.
}

\begin{abstract}
Aims To determine how spontaneous panic and agoraphobia relate longitudinally, and to estimate the incidence rate of and other possible risk factors for first-onset agoraphobia, using a general population cohort.
\end{abstract}

Method A sample of 1920 adults in east Baltimore were assessed in 1981-1982 and the mid-1990s with the Diagnostic Interview Schedule (DIS). Psychiatrist diagnoses were made in a subset of the sample at follow-up $(n=816)$.

Results Forty-one new cases of DIS/ DSM-III-R agoraphobia were identified (about 2 per 1000 person-years at risk). As expected, baseline DIS/DSM-III panic disorder predicted first incidence of agoraphobia ( $O R=12,95 \%$ Cl 3.2-45), as did younger age, female gender and other phobias. Importantly, baseline agoraphobia without spontaneous panic attacks also predicted first incidence of panic disorder ( $\mathrm{OR}=3.9,95 \% \mathrm{Cl}$ I.8-8.4). Longitudinal relationships between panic disorder and psychiatrist-confirmed agoraphobia were strong (panic before agoraphobia $\mathrm{OR}=20,95 \% \mathrm{Cl}$ 2.3-180; agoraphobia before panic $\mathrm{OR}=16,95 \% \mathrm{Cl} 3.2-78$ ).

Conclusions The implied one-way causal relationship between spontaneous panic attacks and agoraphobia in DSM-IV appears incorrect.

Declaration of interest None.
The DSM-IV implies that agoraphobia is almost always a consequence of spontaneous panic attacks (American Psychiatric Association, 1994, 2000). Recent editions of the DSM have been influenced by the work of Klein (1980) and others, whose patients usually reported that their agoraphobic symptoms followed unexpected spells of panic. Although epidemiological studies found many people with agoraphobia but no history of panic, typical epidemiological methods, employing fully structured non-clinician interviews, were suspect (Horwath et al, 1993). Also, although retrospective investigations found that agoraphobic symptoms preceded panic in some patients with both conditions (reviewed in Fava \& Mangelli, 1999), the authors of DSM-IV were concerned about possible recall bias (Craske, 1996) given the absence of prospective longitudinal studies such as the one reported here. We sought to determine first, how spontaneous panic and agoraphobia relate longitudinally, and second, the incidence rate of and other possible risk factors for firstonset agoraphobia, using a longitudinally assessed general population cohort, with clinical reappraisal at follow-up to assess effects of possible diagnostic misclassification.

\section{METHOD}

\section{Sample}

The Epidemiologic Catchment Area (ECA) programme was completed in five centres in the USA from 1981 to 1982 (Regier et al, 1984). Trained non-clinician interviewers administered the National Institute of Mental Health Diagnostic Interview Schedule (DIS; Robins et al, 1981) to a probabilistic sample of the adult population in each centre at two points in time, separated by a 1-year interval. In Baltimore, the original sample included 3481 participants (Fig. 1).
Between 1993 and 1996, in the Baltimore ECA Follow-up Study, $88 \%$ of the original Baltimore cohort were traced, and $73 \%$ of those known to be alive were interviewed again using the DIS $(n=1920)$. The survey method is described in detail elsewhere (Eaton et al, 1997). Briefly, the same survey procedures were used as in 1981. The interview was augmented with a life chart, in order to assist recall over the follow-up period. Mortality in the intervening 13 years was substantial as a result of the high proportion of elderly respondents originally sampled at this site. Neither baseline phobias nor panic disorder were significant predictors of loss to follow-up or refusal to participate in the follow-up study, although phobias were weakly predictive of mortality between interview waves (Badawi et al, 1999).

A subset of the 1920 participants in the Baltimore ECA Follow-up Study was additionally interviewed by psychiatrists $(n=816)$. Individuals were selected for this interview mainly if they showed evidence of Axis I psychopathology (especially with the DIS) in 1981 and/or in the Follow-up Study, although about a quarter were selected at random from the remaining members of the sample (Samuels et al, 2002). A total of 816 persons participated in the psychiatric evaluation, which included the use of a semi-structured diagnostic instrument, the Schedule for Clinical Assessment in Neuropsychiatry (SCAN; Wing et al, 1990). Participants provided informed consent for each interview, and the current study was approved by the Johns Hopkins Medicine Institutional Review Board 3.

\section{Diagnostic interviews}

The version of the DIS used in the first two interview waves (1981 and 1982) included a general description of a phobia ('such a strong fear of something or some situation that [you] try to avoid it, even though [you] know there is no real danger'), followed by screening questions about fears of 'tunnels or bridges', 'public transportation (airplanes, buses, elevators)', 'crowds', 'going out of the house alone' and 'being alone'. If respondents acknowledged having any of these unreasonable fears that resulted in avoidance and 'interfered with (their lives) or activities a lot', they were given DIS/DSM-III diagnoses of agoraphobia (Boyd et al, 1985). As noted by Weissman et al (1986), the DIS did not 


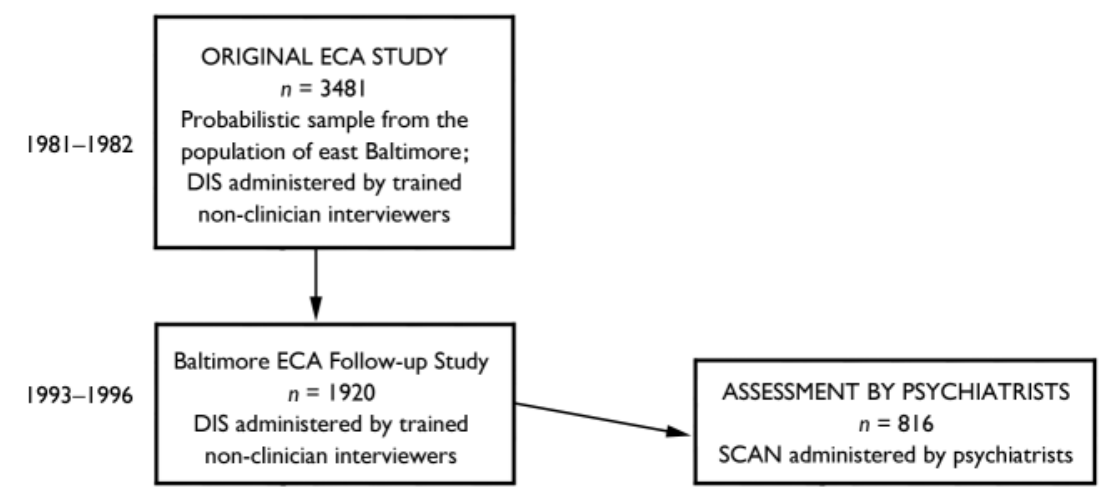

Fig. I Overview of the Baltimore Epidemiologic Catchment Area (ECA) Study. DIS, Diagnostic Interview Schedule; SCAN, Schedules for Clinical Assessment in Neuropsychiatry.

address the DSM-III concept of agoraphobia as 'fear of being in a place from which escape might be impossible or difficult in case of incapacitation' (American Psychiatric Association, 1980).

The version of the DIS used from 1993 to 1996 was modified to reflect the changes in diagnostic criteria in DSM-III-R (American Psychiatric Association, 1987). Screening questions for agoraphobia read:

(a) 'Some people have such an unreasonable fear of being in a crowd, travelling in buses, cars or trains, or crossing a bridge that they always get very upset in such a situation or avoid it altogether. Did you ever go through a period when being in such a situation always frightened you badly?'

(b) 'Did you ever have such an unreasonably strong fear of being alone away from home that you always got very upset in this situation, or you avoided it altogether?'

(c) 'Have you ever had an unreasonable fear of being alone in your own home?'

If positive, these screening questions were followed with questions pertaining to onset, recency, associated anxiety symptoms and level of interference (including limits on being able to travel or leave home). In order to meet DIS/DSM-III-R criteria for agoraphobia, respondents had to endorse at least one of the screening questions, as well as at least one associated anxiety symptom (specifically dizziness, palpitations, nausea/vomiting, feeling of loss of control of bodily functions, or derealisation) and interference. Again, the nature of the fear was not directly assessed, only the typical situations in which such fear was likely to occur.
Psychiatrists made agoraphobia diagnoses according to DSM-III-R criteria, using the SCAN. Agoraphobic fears were grouped together, with the following six probes: 'being in a public place when alone, open spaces, empty streets', 'crowds, shops, theatres - places with no easy exit', 'travelling alone - buses, trains, planes', 'going out alone - being alone away from home', 'collapsing while alone or with no help near' and 'being alone indoors'. The SCAN glossary describes agoraphobia as anxiety related to being in such situations, lessened in the presence of a trusted companion. The anxiety is related to difficulty escaping quickly (feeling trapped) or leaving without embarrassment, or fear of being incapacitated, with no help near. Thus, psychiatrists administering the SCAN assessed the nature of the fears, not just the situations in which they occurred.

\section{Defining incident DIS/DSM-III-R agoraphobia}

In the follow-up sample, 221 cases of lifetime DIS/DSM-III agoraphobia were identified at wave 1 (1981); in these cases the individuals were considered not at risk for incidence of the disorder. Of the remaining participants, 1557 were considered at risk for development of the disorder during the 13 years of follow-up, and 140 had missing data. Incident cases for this study were those who were at risk and met criteria for lifetime DSM-III-R agoraphobia at wave 3 (1993-1996). Participants with incident DIS/DSM-III agoraphobia at wave $2(1982, n=3)$ were considered new cases only if they met DSM-III-R criteria at wave 3 as well $(n=1)$. Given the multiwave nature of the study, there was a potential for discrepancies in timing of onsets
(Rubio-Stipec et al, 1992). Seventeen respondents with incident DSM-III-R agoraphobia reported no disorder-level symptoms in the first wave but, at followup, reported the onset of their earliest related fears as before 1981 . It should be noted that the DIS-III-R did not assess age at onset of associated symptoms or interference, so these respondents could have had agoraphobia-related fears without meeting full criteria for agoraphobia until the follow-up period. Consistent with this, we found that more than half of these individuals (9 out of 17) reported 'subthreshold' DIS/agoraphobia-related fears in 1981. An additional three people reported that both the onset and offset of their fears occurred before 1981. All 20 were considered incident cases (in effect, giving priority to the time of assessment data and assuming errors in recall for the three respondents mentioned above). We conducted additional analyses in which these three cases were excluded, and there was no substantive difference in results. There were also slight differences in the screening questions for DIS/DSM-III-R agoraphobia; that is, it was conceivable that participants with phobias of riding in cars or trains were missed with the DIS/ DSM-III interview and incorrectly classified as incident DIS/DSM-III-R cases. However, we found that incident cases of DIS/DSM-III-R agoraphobia respondents who endorsed items containing these fears were, if anything, less likely to report onset before 1981, compared with those who endorsed items containing the same situations in both interviews (further information available from the author on request).

\section{Statistical analysis}

A weighted cumulative incidence proportion was calculated with an elaboration of the Woodbury down-weighting procedure (Kessler et al, 1985). This procedure was developed for the ECA programme to ensure that parameter estimates were accurate. Weighting, in this case, corrects the parameter estimate by the probability of selection into the sample; also, it adjusts for non-response to replicate the target population of survivors, according to age, ethnicity and gender categories. Putative baseline risk factors, including demographic factors and lifetime psychiatric diagnoses (as recorded in 1981), were examined in relation to subsequent development of agoraphobia. Baseline 
agoraphobia (with and without a history of spontaneous panic attacks) and other Axis I conditions were also examined in relation to subsequent development of panic disorder. Univariate and adjusted odds ratios were generated in logistic regression analyses.

\section{RESULTS}

\section{Incidence of agoraphobia}

There were 41 new cases of DIS/DSM-III-R agoraphobia identified among the 1557 participants at risk. Of these, $14(34 \%)$ reported fears of being in a crowd or standing in line; $10(24 \%)$ reported fears of riding on trains or buses, planes or in a car; $14(34 \%)$ reported fears of crossing a bridge; 11 $(27 \%)$ reported fears of being alone away from home and $11(27 \%)$ reported fears of being alone at home. The unweighted 13-year cumulative incidence proportion of DIS/DSM-III-R agoraphobia is estimated at 2.6 per 100 persons at risk. The weighted 13-year cumulative incidence proportion is estimated at 2.4 per 100 persons at risk. These estimates correspond to an annual incidence rate of approximately 2 per 1000. The mean age at onset of agoraphobia-related fears for these incident cases was 21.2 years $($ s.d. $=16.8$ ).

\section{Baseline demographic characteristics and incident agoraphobia}

The 41 respondents with incident DIS/ DSM-III-R agoraphobia were compared with the 1516 respondents who were at risk but did not develop agoraphobia. Younger age, female gender, African American ethnicity and having never married (at baseline, 1981) were statistically significant predictors of incident agoraphobia in univariate models (Table 1 ). The odds ratio for incident agoraphobia was more than twice as high in young adults (18-29 years old at baseline) compared with middle-aged adults (45-64 years old; there was no new case among those over 65 years old), and more than three times as high in women. When age group and gender were taken into account, ethnicity and marital status were not significantly related to incidence (e.g. as might be expected, younger participants were less likely to be married).

Table I Odds of first-onset agoraphobia over a 13-year period, given baseline (198I) demographic characteristics

\begin{tabular}{|c|c|c|c|c|c|}
\hline \multicolumn{2}{|c|}{ New-onset agoraphobia' } & \multicolumn{2}{|c|}{ Univariate } & \multicolumn{2}{|c|}{ Adjusted $^{2}$} \\
\hline Present & Absent & OR & $(95 \% \mathrm{Cl})$ & OR & $(95 \% \mathrm{Cl})$ \\
\hline$n$ & $n$ & & & & \\
\hline
\end{tabular}

\begin{tabular}{|c|c|c|c|c|c|c|}
\hline \multicolumn{7}{|l|}{ Age, years } \\
\hline $18-29$ & 21 & 508 & 1.0 & & 1.0 & \\
\hline $30-44$ & 14 & 455 & 0.7 & $(0.4-I .5)$ & 0.7 & $(0.4-I .4)$ \\
\hline $45-64$ & 6 & 385 & 0.4 & $(0.2-0.9)^{*}$ & 0.3 & $(0.1-0.8)^{*}$ \\
\hline $65-86$ & 0 & 168 & & & & \\
\hline \multicolumn{7}{|l|}{ Gender } \\
\hline Female & 34 & 900 & 3.3 & $(1.5-7.5)^{*}$ & 3.6 & $(1.6-8.2) *$ \\
\hline Male & 7 & 616 & 1.0 & & 1.0 & \\
\hline \multicolumn{7}{|l|}{ Ethnicity } \\
\hline White & 20 & 966 & 1.0 & & 1.0 & \\
\hline African American & 21 & 497 & 2.0 & $(1.1-3.8)^{*}$ & 1.6 & $(0.8-2.9)$ \\
\hline Other & 0 & 53 & & & & \\
\hline \multicolumn{7}{|l|}{ Education $^{3}$} \\
\hline Up to grade 8 & 2 & 126 & 0.7 & $(0.2-3.6)$ & 1.5 & $(0.3-7.8)$ \\
\hline Grades 9-II & 14 & 378 & 1.7 & $(0.7-4.2)$ & 1.9 & $(0.8-4.7)$ \\
\hline Grade 12 & 16 & 504 & 1.5 & $(0.6-3.5)$ & 1.4 & $(0.6-3.3)$ \\
\hline More than grade 12 & 8 & 377 & 1.0 & & 1.0 & \\
\hline \multicolumn{7}{|l|}{ Marital status ${ }^{3}$} \\
\hline Married & 13 & 701 & 1.0 & & 1.0 & \\
\hline Widowed & I & 143 & 0.4 & $(0.0-2.9)$ & 0.6 & $(0.1-5.0)$ \\
\hline Separated & 6 & 128 & 2.5 & $(0.9-6.8)$ & 2.0 & $(0.7-5.3)$ \\
\hline Divorced & 3 & 143 & I.I & $(0.3-4.0)$ & 1.0 & $(0.3-3.5)$ \\
\hline Never married & 18 & 400 & 2.4 & $(1.2-5.0)^{*}$ & 1.9 & $(0.9-4.3)$ \\
\hline \multicolumn{7}{|c|}{ Annual household income ${ }^{3}$} \\
\hline Up to $\$ 4999$ & 8 & 191 & 4.6 & $(0.6-38)$ & 3.8 & $(0.4-3 I)$ \\
\hline$\$ 5000-9999$ & 5 & 223 & 2.5 & $(0.3-22)$ & 2.4 & $(0.3-2 I)$ \\
\hline$\$ 10000-14999$ & 7 & 252 & 3.1 & $(0.4-25)$ & 2.6 & $(0.3-22)$ \\
\hline$\$ 15000-19999$ & 4 & 199 & 2.2 & $(0.2-20)$ & 2.1 & $(0.2-20)$ \\
\hline$\$ 20000-34999$ & 9 & 417 & 2.4 & $(0.3-19)$ & 2.3 & $(0.3-18)$ \\
\hline$>\$ 35000$ & I & III & 1.0 & & 1.0 & \\
\hline
\end{tabular}

$* P \leqslant 0.05$.

I. Diagnosed with the Diagnostic Interview Schedule modified to reflect DSM-III-R criteria.

2. Adjusted for age group and gender.

3. Education, marital status and household income data were missing for $n=132, n=\mid$ and $n=130$ respectively.

\section{Baseline Axis I disorders and incident agoraphobia}

In univariate analyses, participants with lifetime DIS/DSM-III major depression, spontaneous panic attacks (not cued by phobic stimuli), panic disorder and other phobias at baseline (i.e. in 1981) were significantly more likely to develop agoraphobia over the follow-up period, compared with those without these conditions at baseline (Table 2). By far the strongest predictor of incident agoraphobia was baseline panic disorder (unadjusted
$\mathrm{OR}=12$, as opposed to odds ratios of about 3-4 for the other significant Axis I predictors). The relationships between baseline major depression or spontaneous panic attacks and incident agoraphobia were no longer statistically significant when age group and gender were taken into account. Although baseline alcohol use disorders did significantly predict onset of agoraphobia when these demographic factors (particularly gender) were taken into account (women were less likely to have baseline alcohol use disorders), this relationship was not significant when baseline comorbid 
Table 2 Odds of first-onset agoraphobia over a |3-year period, given baseline (198I) lifetime Axis I disorders

\begin{tabular}{|c|c|c|c|c|c|}
\hline \multirow{2}{*}{$\begin{array}{l}\text { Lifetime Axis I } \\
\text { disorder at baseline' }\end{array}$} & \multicolumn{2}{|c|}{ First-onset agoraphobia ${ }^{2}$} & \multirow{2}{*}{$\frac{\text { Univariate }}{\text { OR }(95 \% \mathrm{Cl})}$} & \multirow{2}{*}{$\frac{\text { Adjusted }^{3}}{\text { OR }(95 \% \mathrm{Cl})}$} & \multirow{2}{*}{$\begin{array}{l}\text { Adjusted }^{4} \\
\text { OR }(95 \% \mathrm{Cl})\end{array}$} \\
\hline & $\begin{array}{c}\text { Present } \\
n\end{array}$ & $\begin{array}{c}\text { Absent } \\
n\end{array}$ & & & \\
\hline \multicolumn{6}{|l|}{ Alcohol use disorder } \\
\hline Present & 7 & 172 & $1.6(0.7-3.6)$ & $3.1(1.2-7.8)^{*}$ & $2.4(0.9-6.2)$ \\
\hline Absent & 34 & 1316 & & & \\
\hline \multicolumn{6}{|l|}{ Drug use disorder } \\
\hline Present & 2 & 81 & $0.9(0.2-3.8)$ & $0.8(0.2-3.3)$ & $0.6(0.1-2.7)$ \\
\hline Absent & 38 & 1401 & & & \\
\hline \multicolumn{6}{|l|}{ Major depression } \\
\hline Present & 4 & 50 & $3.1(1.1-9.1)^{*}$ & $2.4(0.8-7.2)$ & $1.5(0.4-5.3)$ \\
\hline Absent & 37 & 1439 & & & \\
\hline \multicolumn{6}{|l|}{ Dysthymia } \\
\hline Present & 2 & 29 & $2.6(0.6-11.2)$ & $1.9(0.4-8.5)$ & $0.3(0.0-3.6)$ \\
\hline Absent & 39 & 1460 & & & \\
\hline \multicolumn{6}{|l|}{ Panic disorder } \\
\hline Present & 3 & 10 & $12(3.2-45)^{*}$ & II $(2.8-46)^{*}$ & $8.3(1.9-35)^{*}$ \\
\hline Absent & 37 & 1478 & & & \\
\hline \multicolumn{6}{|c|}{ Spontaneous panic attack } \\
\hline Present & 3 & 30 & $3.9(1.2-13)^{*}$ & $2.9(0.8-10)$ & $2.1(0.6-7.8)^{5}$ \\
\hline Absent & 37 & 1457 & & & \\
\hline \multicolumn{6}{|l|}{ Other phobia } \\
\hline Present & 13 & 227 & $2.6(1.3-5.1)^{*}$ & $2.3(1.2-4.5)^{*}$ & $2.2(1.1-4.4)^{*}$ \\
\hline Absent & 28 & 1262 & & & \\
\hline
\end{tabular}

$* P \leqslant 0.05$.

I. Diagnosed with the unmodified Diagnostic Interview Schedule (DSM-III).

2. Diagnosed with the Diagnostic Interview Schedule modified to reflect DSM-III-R criteria.

3. Adjusted for baseline age group and gender.

4. Adjusted for baseline age group, gender, alcohol use disorder, panic disorder and other phobia.

5. Adjusted for baseline age group, gender, alcohol use disorder and other phobia.

conditions were also taken into account (i.e. panic disorder and other phobias).

\section{Baseline agoraphobia and other Axis I disorders, and incident panic disorder}

As reported previously by Eaton et al (1998), there were 35 new cases of panic disorder during the follow-up period out of 1731 at risk; demographic risk factors included female gender, younger age and White ethnicity. Significant baseline (1981) Axis I predictors of incident panic disorder included lifetime DIS/DSM-III drug use disorder, major depression, dysthymia, agoraphobia, and agoraphobia without a history of spontaneous panic attacks (last OR=3.9 95\% CI 1.8-8.4) (Table $3)$. However, there was a substantial degree of comorbidity among baseline disorders. When baseline comorbidity was taken into account, agoraphobia was the only significant predictor of incident panic disorder.

\section{Limiting to psychiatrist-confirmed agoraphobia}

Twenty-seven of the participants with incident DIS/DSM-III-R agoraphobia were seen by psychiatrists. Masked to DIS diagnoses, psychiatrists rated 15 of these individuals as having substantial, unambiguous lifetime agoraphobic phenomena, although the psychiatrists thought 6 of these 15 cases were below the rigorous SCAN diagnostic threshold (in all 6 of these cases the individual had at least two agoraphobia-type fears). Of the remaining 12 cases, it appeared that 6 had been misclassified with the DIS (i.e. using the psychiatric interview as the standard); that is, their avoidances were understandable in terms of other kinds of fears. In the latter cases one person had a fear of flying, one had a fear of heights, and four had social and other fears (one was practically housebound with fear of people; the rest had additional fears of enclosed spaces, being attacked or heights/bridges). In the final 6 cases, two people were assessed as unreliable informants, one young woman said that her physician had recommended she avoid stressful situations following possible transient ischaemic attacks, and three appeared to give discrepant answers to similar questions in the two interviews (i.e. the non-clinician-administered DIS and the psychiatrist-administered SCAN).

In addition, 26 participants at risk of DIS/DSM-III-R agoraphobia but without the DIS diagnosis were diagnosed as having agoraphobia by psychiatrists. Twelve of these participants endorsed DIS agoraphobia-related fears but did not endorse sufficient additional criteria for the diagnosis, and 10 appeared to provide discrepant answers to similar questions in the two interviews. In the remaining 4 cases it was possible that psychiatrists administering the SCAN had elicited symptoms not specifically addressed with the DIS: fear of shops and theatres, and fear of collapsing with no help nearby.

For the following analyses, we defined psychiatrist-confirmed incident agoraphobia as present if the participant met criteria for incident DIS/DSM-III-R agoraphobia and was diagnosed by a psychiatrist as having lifetime agoraphobia at follow-up $(n=9)$. We excluded discrepant cases (with unconfirmed incident DIS/DSM-III-R agoraphobia, $n=18$; or psychiatristdiagnosed agoraphobia without the incident DIS diagnosis, $n=26$ ), so the comparison group was also slightly smaller than in the previous sections $(n=1490)$. The pattern of predictors for psychiatristconfirmed incident agoraphobia was similar to that reported above; however, given the restricted number of cases, statistical significance was not usually present. Nevertheless, the expected relationship between baseline DIS/DSM-III panic disorder and psychiatrist-confirmed incident agoraphobia was highly significant $(\mathrm{OR}=20$, 95\% CI 2.3-180). Given the relatively small number of cases here, we did not think it wise to include covariates in the logistic regression models. We also conducted additional analyses of predictors of 'incident' psychiatrist-diagnosed DSM-III-R agoraphobia; cases were classified as incident if they met lifetime criteria at follow-up but did not meet criteria for DIS/DSM-III agoraphobia in $1981(n=35 /$ 667; unconfirmed DIS cases were excluded). As with incident DIS/DSM-III-R agoraphobia, significant predictors included baseline young adult age, female 
Table 3 Odds of first-onset panic disorder over a I3-year period, given baseline (198I) lifetime Axis I disorders

\begin{tabular}{|c|c|c|c|c|c|}
\hline \multirow{2}{*}{$\begin{array}{l}\text { Lifetime Axis I } \\
\text { disorder at baseline' }\end{array}$} & \multicolumn{2}{|c|}{ First-onset panic disorder ${ }^{2}$} & \multirow{2}{*}{$\frac{\text { Univariate }}{\text { OR }(95 \% \mathrm{Cl})}$} & \multirow{2}{*}{$\frac{\text { Adjusted }^{3}}{\text { OR }(95 \% \mathrm{Cl})}$} & \multirow{2}{*}{$\begin{array}{c}\text { Adjusted }^{4} \\
\text { OR }(95 \% \mathrm{Cl})\end{array}$} \\
\hline & $\begin{array}{c}\text { Present } \\
n\end{array}$ & $\begin{array}{c}\text { Absent } \\
n\end{array}$ & & & \\
\hline \multicolumn{6}{|l|}{ Alcohol use disorder } \\
\hline Present & 5 & 195 & $1.2(0.5-3.3)$ & $2.5(0.9-7.1)$ & $1.7(0.6-5.1)$ \\
\hline Absent & 30 & |47| & & & \\
\hline \multicolumn{6}{|l|}{ Drug use disorder } \\
\hline Present & 7 & 96 & 4.1 (1.7-9.6)* & $3.9(1.6-10)^{*}$ & $2.6(1.0-7.0)$ \\
\hline Absent & 28 & 1564 & & & \\
\hline \multicolumn{6}{|l|}{ Major depression } \\
\hline Present & 7 & 66 & $6.1(2.6-14)^{*}$ & $3.7(1.5-9.2)^{*}$ & $2.2(0.8-5.9)$ \\
\hline Absent & 28 & 1602 & & & \\
\hline \multicolumn{6}{|l|}{ Dysthymia } \\
\hline Present & 4 & 33 & $6.4(2.1-19)^{*}$ & $3.8(1.2-12)^{*}$ & $2.4(0.7-8.6)$ \\
\hline Absent & 31 & 1635 & & & \\
\hline \multicolumn{6}{|l|}{ Agoraphobia } \\
\hline Present & II & 169 & $4.1(2.0-8.5)^{*}$ & 3.7 (1.7-7.9)* & $2.9(1.3-6.5)^{*}$ \\
\hline Absent & 24 & 1516 & & & \\
\hline \multicolumn{6}{|c|}{ Agoraphobia without panic ${ }^{5}$} \\
\hline Present & 10 & 161 & $3.9(1.8-8.4)^{*}$ & $3.5(1.6-7.8)^{*}$ & $2.7(1.2-6.1)^{*}$ \\
\hline Absent & 24 & 1516 & & & \\
\hline \multicolumn{6}{|l|}{ Other phobia } \\
\hline Present & 4 & 231 & $2.5(1.3-5.0)$ & $0.7(0.2-2.2)$ & I.I $(0.4-3.4)$ \\
\hline Absent & 31 & 1436 & & & \\
\hline
\end{tabular}

$* P \leqslant 0.05$.

I. Diagnosed with the unmodified Diagnostic Interview Schedule (DSM-III).

2. Diagnosed with the Diagnostic Interview Schedule modified to reflect DSM-III-R criteria.

3. Adjusted for baseline age group, gender and ethnicity.

4. Adjusted for baseline age group, gender, ethnicity, drug use disorder, major depression, dysthymia and agoraphobia.

5. Agoraphobia without a history of spontaneous panic attacks.

6. Adjusted for baseline age group, gender, ethnicity, drug use disorder, major depression and dysthymia.

gender, spontaneous panic attacks and panic disorder (further information available from the author on request).

The good concordance between DIS/ DSM-III-R and psychiatrist-diagnosed (SCAN) incident panic disorder has been reported elsewhere (Eaton et al, 1998). For the purposes of the current analyses, we defined psychiatrist-confirmed baseline agoraphobia as present if DIS/DSM-III agoraphobia was present in 1981 and a psychiatrist made the diagnosis of lifetime agoraphobia at follow-up $(n=15$, of whom 11 had no history of DIS/DSM-III spontaneous panic attacks at baseline). We excluded participants with unconfirmed baseline agoraphobia $(n=97)$. Psychiatristconfirmed baseline agoraphobia, with and without a history of spontaneous panic attacks, was a strong predictor of incident DIS/DSM-III-R panic disorder $(\mathrm{OR}=16$, $95 \%$ CI $3.2-78$ and $\mathrm{OR}=15,95 \%$ CI 3.1-75 respectively); again, given relatively small numbers, we did not include covariates in these models.

\section{DISCUSSION}

\section{Panic and agoraphobia}

A primary goal of this study was to determine how spontaneous panic attacks/panic disorder and agoraphobia relate longitudinally. Consistent with Klein's cogent argument regarding the unconditioned stimulus property of spontaneous panic attacks causing a conditioned avoidance response (Klein, 1980), several previous retrospective clinical studies (reviewed by Craske, 1996; Fava \& Mangelli, 1999) and the one previous community study of incident agoraphobia we know of (Eaton \& Keyl, 1990), baseline spontaneous panic attacks (especially frequent ones, i.e. DSMIII panic disorder) strongly predicted newonset agoraphobia. This finding was not surprising. However, the finding that baseline agoraphobia without spontaneous panic attacks also predicted first-onset panic disorder is clearly inconsistent with Klein's theory. In fact, in the present study, baseline agoraphobia without panic was the only baseline Axis I disorder studied that significantly predicted incident panic disorder when baseline comorbidity was taken into account.

Our results are consistent with previous retrospective reports in which patients with both agoraphobia and panic sometimes reported agoraphobia preceding panic (e.g. Fava et al, 1988; Argyle \& Roth, 1989; Lelliott et al, 1989). Given that the causal relationship between spontaneous panic attacks and agoraphobia does not appear as straightforward as Klein's theory suggests, we suggest that DSM-V should de-emphasise the implied one-way causal relationship from spontaneous panic to agoraphobia and make agoraphobia itself a stand-alone diagnosis again, as in ICD-10 (World Health Organization, 1993). That is, although panic does appear to be a potent risk factor for agoraphobia, agoraphobia also appears to be a risk factor for panic disorder.

Other recent epidemiological research is relevant to Marks's argument that agoraphobia should be a stand-alone diagnosis, like other phobias, often but not always associated with panic (Marks, 1987a). Three cross-sectional community studies that employed rigorous clinical methods found that agoraphobia was sometimes present in people with no history of panic: Wittchen et al (1998) found that many adolescents and young adults had clinicianconfirmed agoraphobia but no history of panic; Hayward et al (2003) found that rigorously defined agoraphobic fear and avoidance, although relatively rare in a sample of high-school students, was usually not associated with a history of panic attacks; and Faravelli et al (2004), who - like many in the USA - were sceptical that agoraphobia without a history of panic existed, found several such cases in their mostly adult sample. Epidemiologists have long noted that one reason clinicians rarely encounter patients with agoraphobia but without panic is that panic itself influences treatment-seeking. Two epidemiological studies have provided empirical evidence that individuals experiencing agoraphobia without panic are less likely to seek psychiatric care (Wittchen et al, 1998; Andrews \& Slade, 2002); however, these studies did not find that such individuals never seek care, so it is important that clinicians recognise agoraphobia in the absence of panic. In the USA at least, many younger clinicians tend to consider the diagnosis of agoraphobia only when their patients 
report panic attacks - this is understandable as a result of changes in recent versions of DSM. Diagnostic criteria clearly influence the conceptualisation of psychiatric conditions, and this is not limited to the clinical setting: if researchers conceptualise agoraphobia only as avoidance of certain situations because of fear of panic, the suffering of many people with agoraphobia is ignored.

One reason Marks contended that agoraphobia is a syndrome is that agoraphobic fears have repeatedly been found to cluster together within individuals, separate from other types of fears (Marks, 1987b; Arrindell et al, 2003). Further support for allowing agoraphobia to stand apart from panic comes from a recent study of data from the National Comorbidity Survey (Kessler et al, 1994), in which Cox et al (2003) found that agoraphobic fears clustered together within individuals whether or not they had a history of panic attacks.

Hettema et al (2005) have recently provided evidence that genetic factors in common may predispose to both agoraphobia and panic disorder, in a cross-sectional multivariate twin study of common anxiety disorders. A genetically informative bivariate longitudinal study of panic and agoraphobia could potentially provide additional information about aetiological mechanisms, in that there may be direct causal paths from the experience of panic to agoraphobia (Klein, 1980) and/or vice versa (Fava \& Mangelli, 1999). Regardless of specific aetiological mechanisms, though, clinicians should keep in mind that agoraphobia without panic appears to be at least a marker of risk for later-onset panic disorder.

\section{Agoraphobia incidence and other predictors}

Eaton \& Keyl (1990) estimated the annual first incidence of DIS/DSM-III agoraphobia at 22 per 1000 population. We believe our estimate of DSM-III-R agoraphobia incidence (approximately 2 per 1000 per year) is likely to be a conservative one for two reasons. First, the 13-year period of risk probably affected recall for some agoraphobic symptoms at follow-up. Second, many of the sample who might have been at risk and developed agoraphobia over the follow-up period were not diagnosed with DIS/DSM-III-R agoraphobia (the number of people apparently misclassified as having agoraphobia with the DIS was smaller than the number of people apparently misclassified as not agoraphobic). Our findings regarding demographic predictors of agoraphobia (i.e. younger age and female gender) were in agreement with those of Eaton \& Keyl (1990).

We found that other baseline phobias also predicted onset of agoraphobia, although these were a much weaker predictor than baseline panic disorder. The difference in strength of this relationship, and the fact that baseline depressive disorders were not significantly related to onset of agoraphobia (at least when demographic correlates were taken into account), suggest a somewhat specific longitudinal relationship between panic disorder and agoraphobia in adults, beyond membership in a larger group of 'internalising' or 'neurotic' disorders (Krueger, 1999; Tyrer, 1985).

\section{Strengths and limitations of the study}

This study's strengths include the use of a longitudinally assessed population-based cohort, with psychiatrist interviews to determine the possible effects of misclassification. To our knowledge, this is the first comprehensive report of longitudinal associations between panic and agoraphobia using a prospective design.

We note the following caveats. First, since the psychiatric interviews were conducted at follow-up, it is possible that some individuals classified here as having baseline (1981) DIS/DSM-III agoraphobia without panic and subsequent first-onset DIS/DSM-III-R panic disorder would have been found to have a history of baseline panic with a thorough clinical assessment of lifetime symptoms at baseline. However, given results of a previous clinical reappraisal of DIS/DSM-III agoraphobia without panic, the most likely form of misclassification by far involved diagnosing simple (specific) phobias as DIS/DSM-III agoraphobia (Horwath et al, 1993). Also, participants who had mild agoraphobia at baseline and developed first-onset panic disorder during the follow-up period could have had worsening of agoraphobia symptoms after the onset of panic, thus making them more likely to be diagnosed with lifetime agoraphobia by psychiatrists at follow-up. This is consistent with our and others' clinical experience; for example, some patients report always being afraid of situations such as driving on expressways or through tunnels, but their agoraphobia symptoms become worse and generalise further after the onset of panic in those situations: see Fava \& Mangelli (1999) for a review. Second, we focused on time-of-interview data, ignoring the specific timing of onset of syndromes between interview waves (e.g. there were seven participants with first onset of both panic disorder and agoraphobia during the followup period). We chose to do this because longitudinally collected time-of-interview data are less susceptible to recall bias, and they are a particular strength of this dataset. Third, since the psychiatric interviews were conducted at follow-up, and only on a selected subset of our sample, it was not possible to adjust incidence rates accurately using this method. Fourth, the relatively small number of cases with psychiatristconfirmed incident DIS/DSM-III-R agoraphobia precluded statistical confirmation of baseline predictors other than panic disorder. Nevertheless, for most cases in which the diagnosis of incident DIS/ DSM-III-R agoraphobia was not confirmed by psychiatrists, the issue was not chiefly frank misclassification (e.g. the symptoms were better conceptualised as another phobia), but rather a combination of stricter thresholds in the psychiatric interviews or inconsistent responses by the participant concerned to similar questions in the two interviews (thus, DIS/ DSM-III-R agoraphobia appears to resemble more closely what clinicians call 'agoraphobia' than did DIS/DSM-III agoraphobia). We gain further confidence in our reported risk factors since we found similar results in predictors of psychiatristdiagnosed 'incident' agoraphobia.

\section{ACKNOWLEDGEMENTS}

The National Institute of Mental Health (grants ROI-MH47447, ROI-MH506I6 and K23-MH6454) supported this study. We thank the many individuals who have taken part over the years as administrators, trainers, interviewers and participants in the Baltimore Epidemiologic Catchment Area Study.

\section{REFERENCES}

American Psychiatric Association (1980) Diagnostic and Statistical Manual of Mental Disorders (3rd edn) (DSM-III). Washington, DC: APA.

American Psychiatric Association (1987) Diagnostic and Statistical Manual of Mental Disorders (3rd edn, revised) (DSM-III-R). Washington, DC: APA.

American Psychiatric Association (1994) Diagnostic and Statistical Manual of Mental Disorders (4th edn) (DSM-IV). Washington, DC: APA. 
American Psychiatric Association (2000) Diagnostic and Statistical Manual of Mental Disorders (4th edn, text revision) (DSM-IV-TR). Washington, DC: APA.

Andrews, G. \& Slade, T. (2002) Agoraphobia without a history of panic disorder may be part of the panic disorder syndrome. Journal of Nervous and Mental Disease, 190, 624-630.

Argyle, N. \& Roth, M. (1989) The phenomenological study of 90 patients with panic disorder. Psychiatric Developments, 3, 187-209.

Arrindell, W. A., Eisemann, M., Richter, J., et al (2003) Phobic anxiety in II nations. Part I: Dimensional constancy of the five-factor model. Behaviour Research and Therapy, 4I, 46I-479.

Badawi, M. A., Eaton, W. W., Myllyluoma, J., et al (1999) Psychopathology and attrition in the Baltimore ECA 15-year follow-up 198I-1996. Social Psychiatry and Psychiatric Epidemiology, 34, 91-98.

Boyd, J. H., Robins, L. N., Holzer, C. E., et al (1985) Making diagnoses from DIS data. In Epidemiologic Field Methods in Psychiatry: The NIMH Epidemiologic Catchment Area Program (eds W.W. Eaton \& L. G. Kessler), pp. 209-23I. Orlando, FL: Academic Press.

Cox, B. J., McWilliams, L. A., Clara, I. P., et al (2003) The structure of feared situations in a nationally representative sample. Journal of Anxiety Disorders, 17 89-101.

Craske, M. G. (1996) Is agoraphobic avoidance secondary to panic attacks? In DSM-IV Sourcebook (eds T. A. Widiger, A. J. Frances, H. A. Pincus, et al), pp. 448-459. Washington, DC: American Psychiatric Association.

Eaton,W.W. \& Keyl, P. (1990) Risk factors for the onset of Diagnostic Interview Schedule/DSM-III agoraphobia in a prospective, population-based study. Archives of General Psychiatry, 47, 819-824.

\section{Eaton, W. W., Anthony, J. C., Gallo, J., et al (1997)} Natural history of Diagnostic Interview Schedule/ DSM-IV major depression: the Baltimore Epidemiologi Catchment Area follow-up. Archives of General Psychiatry, 54, 993-999.

Eaton, W. W., Anthony, J. C., Romanoski, A., et al (1998) Onset and recovery from panic disorder in the Baltimore Epidemiologic Catchment Area follow-up. British Journal of Psychiatry, 173, 501-507.

Faravelli, C., Abrardi, L., Bartolozzi, D., et al (2004) The Sesto Fiorentino study: point and one-year prevalences of psychiatric disorders in an Italian community sample using clinical interviewers. Psychotherapy and Psychosomatics, 73, 226-234.

Fava, G. A. \& Mangelli, L. (1999) Subclinica symptoms of panic disorder: new insights into pathophysiology and treatment. Psychotherapy and Psychosomatics, 68, 28I-289.

Fava, G. A., Kellner, R. \& Zielezny, M. A. (1988) Prodromal symptoms in panic disorder with agoraphobia. American Journal of Psychiatry, 145 , 1564-1567.

Hayward, C., Killen, J. D. \& Taylor, C. B. (2003) The relationship between agoraphobia symptoms and panic disorder in a non-clinical sample of adolescents. Psychological Medicine, 33, 733-738.

Hettema, J. M., Prescott, C. A., Myers, J. M., et al (2005) The structure of genetic and environmental risk factors for anxiety disorders in men and women. Archives of General Psychiatry, 62, 182-189.

Horwath, E., Lish, J. D., Johnson, J., et al (1993) Agoraphobia without panic: clinical reappraisal of an epidemiologic finding. American Journal of Psychiatry, $\mathbf{I 5 0}$ |496-|50|.

\section{CLINICAL IMPLICATIONS}

- Agoraphobia without panic appears to be a risk factor, or at least a marker of risk, for the onset of panic.

- Clinicians should be aware that agoraphobia can exist without a history of panic, despite what is implied in DSM-IV.

Young women are at greatest risk for the onset of agoraphobia.

\section{LIMITATIONS}

- Non-clinician-administered, fully structured interviews such as the Diagnostic Interview Schedule sometimes misclassify people with other phobias as having agoraphobia.

- Psychiatrists only performed (lifetime) diagnostic interviews at follow-up.

- It was not possible to adjust incidence rates using data obtained from psychiatrists.

O. JOSEPH BIENVENU, MD, PhD, CHIADI U. ONYIKE, MB, BS, MHS, Department of Psychiatry and Behavioral Sciences, Johns Hopkins University School of Medicine, Baltimore, Maryland; MURRAY B. STEIN, MD, MPH, Departments of Psychiatry and Family and Preventive Medicine, University of California, San Diego, California; LI-SHIUN CHEN, MD, ScD, Department of Psychiatry, Washington University School of Medicine, St Louis, Missouri; JACK SAMUELS, PhD, GERALD NESTADT, MB, BCh, MPH, Department of Psychiatry and Behavioral Sciences, Johns Hopkins University School of Medicine, Baltimore, Maryland; WILLIAM W. EATON, PhD, Department of Mental Health, Johns Hopkins University Bloomberg School of Public Health, Baltimore, Maryland, USA

Correspondence: Dr O. J. Bienvenu, 600 North Wolfe Street, Meyer I0I, Baltimore, MD 21287, USA. Tel: + I 410614 9063; fax: + 410614 5913; e-mail: jbienven@jhmi.edu

(First received 4 March 2005, final revision 6 June 2005, accepted I July 2005)

Kessler, L. G., Folsom, R., Royall, R., et al (1985) Parameter and variance estimation. In Epidemiologic Field Methods in Psychiatry: The NIMH Epidemiologic Catchment Area Program (eds W.W. Eaton \& L. G. Kessler), pp. 327-349. Orlando, FL: Academic Press.

\section{Kessler, R. C., McGonagle, K. A., Zhao, S., et al} (1994) Lifetime and I2-month prevalence of DSM-III-R psychiatric disorders in the United States: results from the National Comorbidity Survey. Archives of General Psychiatry, 5I, 8-19.

Klein, D. F. (1980) Anxiety reconceptualized. Comprehensive Psychiatry, 2I, 4II-427.

Krueger, R. F. (1999) The structure of common menta disorders. Archives of General Psychiatry, 56, 921-926.

Lelliott, P., Marks, I., McNamee, G., et al (1989) Onset of panic disorder with agoraphobia: toward an integrated model. Archives of General Psychiatry, 46, 1000-1004.

Marks, I. M. (1987a) The agoraphobic syndrome (panic disorder with agoraphobia). In Fears, Phobias, and Rituals: Panic, Anxiety, and Their Disorders, pp. 323-36 New York: Oxford University Press.

Marks, I. M. (1987b) Phobic and obsessive-compulsive phenomena: classification, prevalence, and relationship to other problems. In Fears, Phobias, and Rituals: Panic, Anxiety, and Their Disorders, pp. 290-296. New York: Oxford University Press.

Regier, D., Myers, J., Kramer, M., et al (1984) The NIMH Epidemiologic Catchment Area program: historical context, major objectives, and study population characteristics. Archives of General Psychiatry, 4I, 934-94I.

Robins, L. N., Helzer, J. E., Croughan, J., et al (1981) National Institute of Mental Health Diagnostic Interview Schedule: its history, characteristics and validity. Archives of General Psychiatry, 38, 38I-389.

Rubio-Stipec, M., Freeman, D. H., Robins, L., et a (1992) Response error and the estimation of lifetime prevalence and incidence of alcoholism: experience in a community survey. International Journal of Methods in Psychiatric Research, 2 217-224.

Samuels, J., Eaton, W. W., Bienvenu, O. J., et al (2002) Prevalence and correlates of personality disorders in a community sample. British Journal of Psychiatry, $\mathbf{1 8 0}$ 536-542.

Tyrer, P. (1985) Neurosis divisible? Lancet, i, 685-688.

Weissman, M. M., Leaf, P. J., Blazer, D. G., et al (1986) The relationship between panic disorder and agoraphobia: an epidemiologic perspective. Psychopharmacology Bulletin, 22, 787-791.

Wing, J. K., Babor, T., Brugha, T., et al (1990) SCAN Schedules for Clinical Assessment in Neuropsychiatry. Archives of General Psychiatry 47, 589-593.

Wittchen, H.-U., Reed, V. \& Kessler, R. C. (1998) The relationship of agoraphobia and panic disorder in a community sample of adolescents and young adults. Archives of General Psychiatry, 55, 1017-1024.

World Health Organization (1993) The ICD-IO

Classification of Mental and Behavioural Disorders:

Diagnostic Criteria for Research. Geneva: WHO. 